craniotomy per se is of little importance in the development of post-operative epilepsy.

Cases of middle cerebral aneurysm are more common in the epileptic group, as would be expected in view of the distribution of the middle cerebral artery to the fronto-parietal regions and the frequent development of a haematoma in the temporal lobe or the sylvian fissure. This is comparable to the higher incidence of post-traumatic epilepsy when the fronto-parietal areas are involved (Caveness and Liss, 1961). The patients with epilepsy in this series are younger than the average age for the whole group, but this is explained partly by a loading of cases of middle cerebral aneurysm in the younger age-groups.

Fits following subarachnoid haemorrhage are usually generalized, but any type may occur. At the time of the first fit $80 \%$ of the epileptics were not taking anticonvulsants, and the remainder were taking only minimal dosage. Five patients had their first fit more than 18 months after the original illness, and three of these after more than two years. Anticonvulsant therapy should therefore be continued for at least two years, and for those at risk three years. The fits were easily controlled with anticonvulsant therapy; relapses were rare once the patients took the drugs, and, apart from an initial mild midday drowsiness, there were no side-effects from the treatment. Phenobarbitone, $30 \mathrm{mg}$. b.d., is usually sufficient to prevent the attacks; if this dose is inadequate it can be raised to $30 \mathrm{mg}$. t.d.s., and if necessary phenytoin, $100 \mathrm{mg}$. daily t.d.s., may be added.

\section{Summary}

A total of 1,009 cases of ruptured intracranial aneurysm have been studied ; epileptic attacks occurred in $53(10.4 \%)$ of the 508 survivors. The incidence was $14.8 \%$ when a small sample was examined personally.

Fits were more likely to occur in the younger age-group, when the aneurysm was situated on the middle cerebral artery, and in the presence of an intracerebral haematoma. Patients with residual signs of brain damage seemed to be particularly at risk. The fits were usually of the grand-mal type, but focal or temporal-lobe epilepsy also occurred, and different types of fit were occasionally seen in the same patient. Five patients had their first fit more than 18 months after the aneurysm had ruptured.

At the time of the first fit $80 \%$ of the epileptics were not taking anticonvulsants. In most cases the fits were few in number and were well controlled with anticonvulsant therapy. Phenobarbitone, $30 \mathrm{mg}$. b.d., should be given routinely for two years after all cases of ruptured intracranial aneurysm. In cases particularly at risk-for example, younger patients with a ruptured middle cerebral aneurysm associated with an intracerebral haematoma or evidence of residual brain damagethe dose should be increased to $30 \mathrm{mg}$. t.d.s. and continued for three years. If the patient has an attack, phenytoin, $100 \mathrm{mg}$. once to thrice daily, should be added.

We wish to thank Messrs. W. McKissock, L. S. Walsh, and A. E. Richardson for permission to study the patients admitted under their care. We are grateful to Dr. Martin Gardner, of the Social Medicine Research Unit (M.R.C.), for his help in the statistical analysis. The expenses for this work were defrayed by the Wolfson Foundation (F.C.R.) and the National Institutes of Health, Bethesda (M.S.).

\section{REFERENCES}

Caveness, W. F., and Liss, H. R. (1961). Epilepsia (Amst.), 2, 123. Crompton, M. R. (1963). Brain, 86, 30i.

Evans, J. H. (1962). Neurology (Minneap.), 12, 665.

Jennett, W. B. (1962). Epilepsy after Blunt Head Injuries. Heinemann, London.

McKissock, W., Richardson, A., and Walsh, L. (1960). Lancet, 1, 1203.

Richardson, E. P., and Dodge, P. R. (1954). Epilepsia (Amst.), 3, 49.

Richardson, E. P., and Dodge, P. R. (1954).

Rose, F. C. (1964). Rev. Neurol. In press.
Tomlinson, B. E. (1959). f. clin. Path., 12, 391.

Walton, J. N. (1953). Electroenceph. clin. Neurophysiol., 5, 41.
- Assistant Psychiatrist, Prince Henry's Hospital, Melbourne ; formerly Research Fellow in the Department of Child Psychiatry, Guy's Hospital, London. contractures characterized by vasomotor, secretory, and trophic changes are "reflex" and organic in origin, and therefore inaccessible to psychotherapeutic management (Babinski and Froment, 1918). There is, however, adequate evidence that such changes do occur in "hysterical" contracture (Brodie, 1837 ; Briquet, 1859 ; Charcot, 1890), that they are often reversible (Steindler, 1935; Hurst, 1941), and that they are eminently accessible to psychiatric management (Fraser, 1919 ; Macalpine and Ross, 1956).

In this article some characteristics of hysterical contractures in children are described and an approach to their psychiatric management based in part on the principles of learning is discussed.

\section{Clinical Picture}

Six cases of hysterical contracture have been seen in the department of child psychiatry, Guy's Hospital, during the past five years. In three the non-dominant hand was involved. When first seen, the fingers were tightly clenched and initially resistant to even minimal attempts at passive movement. In 
one case the hip-joint was held in a position of abduction and eversion, with consequent disturbance of gait. In another case the ankle-joint was persistently held in the talipes equino-varus position. In the sixth case the toes were maintained in a position of rigid hyperextension. In the latter three cases also passive manipulation of the affected joints was painful and strongly resisted, although in these cases some pain was present even at rest. All six had been intensively investigated and treated for periods ranging from six months to two years. Five of the patients were girls aged 10 to 15 years and one patient was a boy aged 12 . There was a marked similarity in the histories of all children, with respect both to the mode of onset and course of illness and to their family backgrounds.

In every case the symptom had been preceded by some minor "trauma" or orthopaedic procedure. These "injuries" preceded the onset of symptoms by two or three days and were never consistent with the extent or configuration of the ultimate contracture.

The onset of the symptoms was gradual and the course initially fluctuating. A remission was of ten obtained early in the illness by the application of physical treatment-for example, physiotherapy-but was always followed by relapse. Subsequent applications of similar treatment gave progressively disappointing results, and ultimately a fixed and apparently permanent contracture resulted.

Examination of the involved limbs and joints, even at an early stage, usually showed evidence of secondary trophic changes. These were principally cyanosis and coldness of the extremity, oedema, scaling and flaking of the skin, and brittle nails. Where the hand was held in a clenched position the finger-nails continued to grow, causing minor lacerations to the palm that were invariably infected.

Often bizarre postures were maintained without apparent effort. This was in contrast to the marked complaints of pain on even slight movement of the affected joints or limbs. Where passive manipulation was eventually possible a characteristic "to-and-fro" resistance to movement was experienced. No cases displayed any of the characteristic "stigmata " of hysteria -for example, anaesthesia, loss of pharyngeal reflex.

Disturbances between the parents were a common feature. In two cases the separation of father and mother was imminent, while in the remainder there was constant quarrelling and bickering, with subsequent problems of divided loyalties. The parents themselves had often come from broken and unhappy homes. The most characteristic feature was a rigid and authoritarian attitude towards the child, emanating principally from the father. In only one family was there overt evidence of psychiatric disturbance.

Retrospectively a history of severe "stress" coincident with the onset of symptoms could always be obtained. Although mostly involved with difficulties in the home, problems at school were sometimes important-for example, change of school; approach of the $11+$.

The mental state of the children did not display the characteristic belle indifférence encountered frequently in adult patients. They were often, however, depressed, fearful, and anxious regarding the ultimate outcome of their disability.

A history of previous hysterical " conversion" symptoms was present in only one case. However, they all had been subject to minor behaviour disturbances and/or feeding difficulties from an early age.

\section{Management and Results}

The first three cases were managed along orthodox psychodynamic lines utilizing the principles of repression and conversion. Interview techniques were similar to those described by Macalpine and Ross (1956). Therapy was conducted on both an in-patient and an out-patient basis, minimal attention being paid to the symptom itself. In only one case was there appreciable improvement, and here, though treated for more than two years, the hand remained at that time non-functional. Because of the bizarre postures and lack of progress in the other two cases an anaesthetic, using thiopentone and suxamethonium chloride, was given to determine the extent of irreversible secondary change that had occurred. Notwithstanding the views of Hurst (1918) it was concluded that such secondary changes did exist (Figs. 1 and 2).

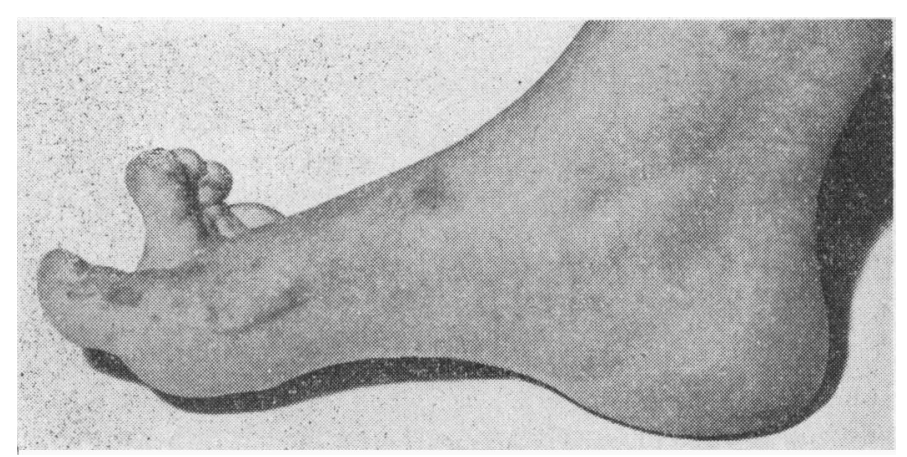

FIG. 1.-Secondary changes present six months.

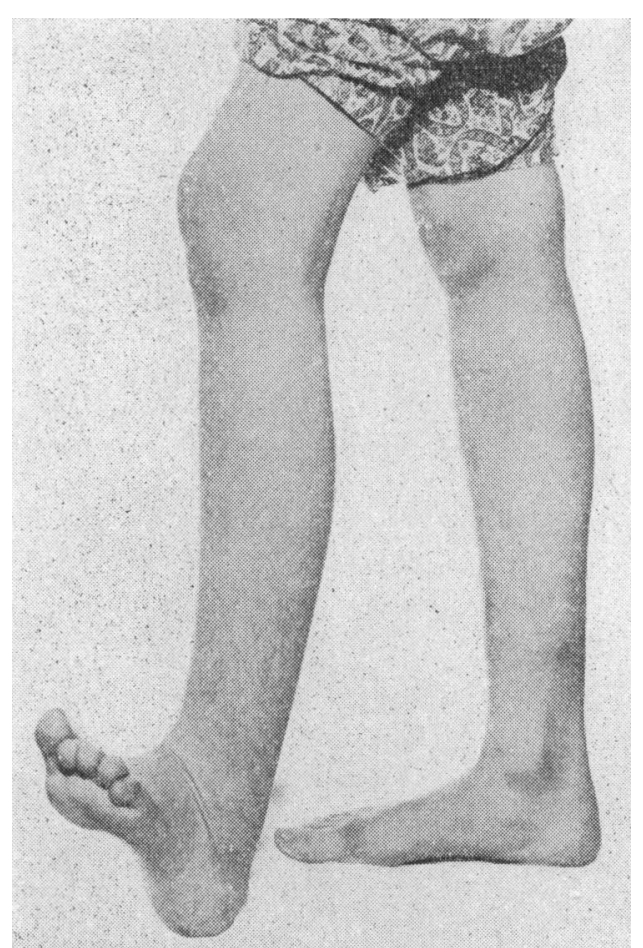

Fig. 2.-Secondary changes present twelve months.

The next three cases were managed by a regime which paid much greater attention to the immediate alleviation of the symptom itself. The initial interview was spent in historytaking, and assurances were given that the symptom was understood and was readily amenable to treatment. An explanation of its aetiology was made in terms of the relationship between anxiety, tension, and muscular spasm. The parents were subsequently interviewed and the same assurances and explanations given. At the ensuing interview passive movements, which did not cause pain, were performed, being followed by vigorously encouraged active movement. The children were instructed to carry out these movements between interviews, and the active part which they themselves played in their treatment was emphasized.

At the end of the third session further history connected with both home and school environment was elicited, and, acting on the information obtained, environmental manipulation, parental counselling, or more assiduous goal-directed psychotherapy (Finesinger, 1948) was undertaken with the patient. 
All these three cases recovered full function of the limb involved within a maximum of four sessions. In two cases the same or similar symptoms returned soon afterwards, but these were handled successfully in an identical manner during one session. No patient was seen for more than 10 interviews. Follow-up of these patients at 21,12 , and 9 months respectively found them all well adjusted and asymptomatic.

\section{Discussion}

Failure to make an early and correct diagnosis of hysterical contracture inevitably raises the problem of irreversible secondary change in the affected limbs. Traditional psychotherapeutic management, which for the most part ignores the symptom, may in this instance be a luxury the physician cannot afford.

The claim of psycho-analysts that symptom removal cannot hope to effect a "cure" except in very recent cases is repudiated by Wolpe (1961), who has advocated that the concepts of motivation and gain be replaced by a theory of the neuroses based on the principles of learning. Without denying that psychological distress may be instrumental in initiating the symptom in these cases, one is still able to offer an alternative explanation for their subsequent potentiation and prolongation.

Startling, bizarre, and incomprehensible symptoms may produce considerable anxiety in a physician who is puzzled over their aetiology. Should this be communicated to a patient, particularly a child, already in psychological distress, puzzled and frightened by the evidence of disordered function which her own body displays, there will be a reinforcement of the mode of behaviour, and the pattern for a prolonged and intractable illness is set. Viewed in this light, hysterical contracture can clearly be an example of "maladaptive learned behaviour" (Wolpe, 1958). Repeated investigations and emphasis on symptoms in any situation, but particularly a structural interpretation, as is most often the case, will serve time and again to reinforce the neurotic behaviour.

The three patients who were treated by reassurance and re-education all had associated psychiatric problems and all required careful handling. These cases were, however, amenable to straightforward psychotherapy or environmental manipulation which could have been given by any psychiatrically sophisticated physician.

The practice of leaving the symptom to sort itself out is, in the case of hysterical contracture, fraught with the extra dangers raised by the possibility of irreversible secondary changes. While such a danger exists, and until early diagnosis can be assured, a more energetic approach to the handling of conversion symptoms of this order must be advocated.

\section{Summary}

Six cases of hysterical contracture in children are described. The need for early recognition and rapid institution of appropriate therapy is outlined, and a method of treatment based on early removal of symptoms is advocated.

Thanks are due to Dr. J. J. Fleminger, physician in psychological medicine, Guy's Hospital, for his enoouragement at the initiation of this project; and to Dr. G. F. Vaughan, physician in child psychiatry, Guv's Hospital, for his advice in the preparation of the paper and for permission to include the case material. This article was prepared while I was in receipt of a grant from the Bloomfield Charitable Trust.

\section{REFERENCES}

Babinski, J., and Froment, J. (1918). In Hysteria or Pithiatism, edited by E. Farquhar Buzzard, London.

Briquet, P. (1859). Traité clinique et thérapeutique de l'hystérie. Baillière, Paris.

Brodie, Sir Benjamin (1837). Lectures Illustrative of Certain Local Nervous Affections. London.

Charcot, J. M. (1890). Cliniques des Maladies du Système Nerveux, 1, 96. Paris.

Finesinger, J. E. (1948). Amer. F. Psychiat., 105, 187.

Fraser, A. C. (1919). Med. F. Aust., 2, 436.

Hurst, Sir Arthur F. (1918). Brit. F. Surg., 6, 579.

(1941). Clin. F., 70, 29.

Macalpine, I., and Ross, Sir James Paterson (1956). Lancet, 1, 78.

Steindler, A.' (1935). Int. Clin., 4, 221.

Wolpe, J. (1958). Psychotherapy by Reciprocal Inhibition. Stanford Univ. Press, Stanford, California.

- (1961). Amer. F. Psychiat., 118, 35.

\title{
Effects of Arterial and Venous Pressure Changes on the Electroencephalogram During Cardiac Operations
}

\author{
ANN HARDEN,* B.Sc.
}

\section{Brit. med. F., 1965, 1, 23-27}

The value of the electroencephalogram (E.E.G.) as a sensitive indicator of changes in cerebral function during cardiac operations has been recognized (Arfel et al., 1961; Storm van Leeuwen et al., 1961 ; Thies-Puppel and Wiemers, 1961). It is known that a fall in blood-pressure during operations on the heart and main vessels may result in an inadequate blood supply to the brain; this is immediately followed by E.E.G. changes when the circulatory alteration is of sufficient duration and severity. The superior vena caval pressure has also been studied during cardiac surgery. Obstruction of venous outflow from the brain by clamping the superior vena cava was shown by Pampiglione and Waterston (1958) often to be followed within 20 to 30 seconds by increasing slow activity in the E.E.G.

\footnotetext{
* Department of Electroencephalography and Clinical Neurophysiology, the Hospital for Sick Children, Great Ormond Street, London.

Other workers (Brechner et al., 1959 ; Kavan and Brechner, 1961) have also said that the level of superior vena caval pressure had an important effect on the electrical activity of the brain during open-heart surgery. It is possible that venous congestion of the brain may be followed by E.E.G. changes whenever the increased venous pressure prevents an adequate supply of arterial blood to the brain (Pampiglione and Waterston, 1961). It has also been suggested that in conditions such as congestive heart failure, in which there is an increase in systemic venous pressure, there is a reduction in cerebral blood flow (Kety, 1950), though no measurements have been reported.

In experiments on dogs, Duffy and Caliva (1961) have shown that an increase in venous pressure is accompanied by a decrease in oxygen availability to the cerebral tissues, probably as a result 